\title{
Rapid Induction of COOLing in Stroke Patients (iCOOL1): a randomised pilot study comparing cold infusions with nasopharyngeal cooling
}

Sven Poli ${ }^{1,2}$, Jan Purrucker ${ }^{1}$, Miriam Priglinger ${ }^{1}$, Matthias Ebner ${ }^{2}$, Marek Sykora ${ }^{1}$, Jennifer Diedler ${ }^{1,2}$, Cem Bulut $^{3}$, Erik Popp ${ }^{4}$, André Rupp ${ }^{1}$ and Christian Hametner ${ }^{1 *}$

\begin{abstract}
Introduction: Induction methods for therapeutic cooling are under investigated. We compared the effectiveness and safety of cold infusions (Cl) and nasopharyngeal cooling (NPC) for cooling induction in stroke patients.

Methods: A prospective, open-label, randomised (1:1), single-centre pilot trial with partially blinded safety endpoint assessment was conducted at the neurointensive care unit of Heidelberg University. Intubated stroke patients with an indication for therapeutic cooling and an intracranial pressure (ICP)/temperature brain probe were randomly assigned to $\mathrm{Cl}\left(4^{\circ} \mathrm{C}, 2 \mathrm{~L}\right.$ at $\left.4 \mathrm{~L} / \mathrm{h}\right)$ or NPC $(60 \mathrm{~L} / \mathrm{min}$ for $1 \mathrm{~h})$. Previous data suggested a maximum decrease of tympanic temperature for $\mathrm{Cl}(2.1 \mathrm{~L}$ within $35 \mathrm{~min}$ ) after $52 \mathrm{~min}$. Therefore the study period was 1 hour (15 min subperiods I-IV). The brain temperature course was the primary endpoint. Secondary measures included continuous monitoring of neurovital parameters and extracerebral temperatures. Statistical analysis based on repeated-measures analysis of variance.

Results: Of 221 patients screened, 20 were randomized within 5 months. Infusion time of $2 \mathrm{~L} \mathrm{Cl}$ was $33 \pm 4$ min in 10 patients and 10 patients received NPC for 60 min. During active treatment (first $30 \mathrm{~min}$ ), brain temperature decreased faster with $\mathrm{Cl}$ than during NPC (I: $-0.31 \pm 0.2$ versus $-0.12 \pm 0.1^{\circ} \mathrm{C}, P=0.008 ; 1 \mathrm{ll}-1.0 \pm 0.3$ versus $-0.49 \pm 0.3^{\circ} \mathrm{C}$, $P=0.001)$. In the Cl-group, after the infusion was finished, the intervention no longer decreased brain temperature, which increased after $3.5 \pm 3.3 \mathrm{~min}$. Oesophageal temperature correlated best with brain temperature during $\mathrm{Cl}$ and NPC. Tympanic temperature reacted similarly to relative changes of brain temperature during $\mathrm{Cl}$, but absolute values slightly differed. Cl provoked three severe adverse events during subperiods II-IV (two systolic arterial pressure (SAP), one shivering) compared with four in the NPC-group, all during subperiod I (three SAP, one ICP). Classified as possibly intervention-related, two cases of ventilator failure occurred during NPC.
\end{abstract}

Conclusions: In intubated stroke patients, brain cooling is faster during Cl than during NPC. Importantly, contrary to previous expectations, brain cooling stopped soon after $\mathrm{Cl}$ cessation. Oesophageal but neither bladder nor rectal temperature is suited as surrogate for brain temperature during $\mathrm{Cl}$ and NPC. Several severe adverse events in $\mathrm{Cl}$ and in NPC demand further studying of safety.

Trial registration: ClinicalTrials.gov NCT01573117. Registered 31 March 2012

\section{Introduction}

Experimental data suggest that compared with late treatment initiation, early commencement of cooling delivers superior neuroprotection in cardiac arrest and stroke [1,2]. Several methods for induction of therapeutic cooling are available [3], but these methods are underinvestigated with

\footnotetext{
* Correspondence: christian.hametner@med.uni-heidelberg.de

${ }^{1}$ Department of Neurology, Heidelberg University, INF 400, 69120 Heidelberg, Germany

Full list of author information is available at the end of the article
}

regard to their effects on the brain and neurovital parameters [4]. The present study focused on intravenous cold infusions $(\mathrm{CI})$ and the RhinoChill device for nasopharyngeal cooling (NPC; BeneChill, Inc., San Diego, CA, USA).

$\mathrm{CI}$ represent the current clinical standard for hypothermia induction in cardiac arrest [5-7] and are presently being used for induction of hypothermia in two large trials investigating the outcome of stroke [8,9]. However, no evidence exists on the efficacy of $\mathrm{CI}$ with regard to 
brain temperature - the primary target for neuroprotection [10]. Measuring tympanic temperature in stroke patients, previous data of CI ( $2.1 \mathrm{~L}$ within 35 minutes) showed a maximum temperature decrease, in mean, of $1.6^{\circ} \mathrm{C}$ after 52 minutes [11]. Data on the safety of CI in stroke patients are also urgently needed. The usefulness of four observational studies ( $\mathrm{n}=3$ to 36) [11-14] and one small randomised controlled trial $(\mathrm{n}=10)$ [15] is limited by their intermittent rather than continuous circulatory measurements when administering $\mathrm{CI}$, and no data are available on neuromonitoring. Furthermore, a cardiac arrest trial recently found that early hypothermia induction with CI improved neither the survival nor the neurological status of the patients and was associated with an increased rate of pulmonary oedema [16].

NPC is a new method to induce cooling. Both Castrén and Busch with their respective colleagues demonstrated the feasibility and safety of NPC in the prehospital cardiac arrest setting $[17,18]$, and Abou-Chebl et al. provided data on brain cooling in brain-injured patients $\left(-1.4^{\circ} \mathrm{C}\right.$ within one hour) [19]. We confirmed this cooling rate in stroke patients $\left(-1.2^{\circ} \mathrm{C}\right.$ after 58 minutes), but highlighted critical rises in blood pressure (BP) as a potentially important adverse effect (AE), warranting further investigation [20].

The Rapid Induction of COOLing in Stroke Patients trial (iCOOL1) is investigating, for the first time, the effect of $\mathrm{CI}$ on brain temperature and comparing $\mathrm{CI}$ and NPC in their brain cooling efficacy and safety during cooling induction. Secondary measures comprise a safety evaluation, including continuous monitoring of neurovital parameters, and the analysis of temperature dynamics at different extracerebral monitoring sites to find a valid surrogate for brain temperature during cooling induction with either CI or NPC.

\section{Materials and methods Study design, approval}

iCOOL1 is a prospective, interventional, open-label, twoarmed, randomised, single-centre pilot trial with partially blinded safety endpoint assessment (see Randomisation and blinding). Clinical Trial Registration Information [21] unique identifier is NCT01573117. Institutional Review Board approval was obtained from the ethics committee of Heidelberg University (protocol no. S-301/2010). Informed consent was obtained from patients (whenever competent) or their legal representatives before enrolment in the study.

\section{Setting and eligibility criteria}

The study was conducted at the neurointensive care unit (NICU) of the Department of Neurology at Heidelberg University, a tertiary care hospital including a neurovascular centre.
Our NICU has 12 ventilator-equipped beds and more than 200 severe stroke patients are treated per year. Between June and November 2011 all admitted patients were screened and, if eligible, enrolled prospectively. The inclusion and exclusion criteria are listed in Table 1.

In all patients, neurological intensive care physicians had prescribed therapeutic cooling and placement of a combined intracranial pressure (ICP)/temperature brain probe independent of the study (Neurovent Temp or Neurovent PTO, accuracy $\pm 0.1^{\circ} \mathrm{C}$; Raumedic, Muenchberg, Germany; inserted $>3 \mathrm{~cm}$ below the cortical surface). According to our standard operating procedure, therapeutic cooling targeting normothermia is indicated when body core temperature rises above $37.2^{\circ} \mathrm{C}$ [22]. Therapeutic hypothermia as a compassionate measure for treatment of cerebral oedema has been implemented at our institution since 1998 [23], even though the treatment is experimental. All patients were intubated and deeply sedated and showed no response to painful stimuli, including pinching of the nasal septum (RASS-5, Richmond Agitation Sedation Scale). Our standard regimen for sedation and analgesia included the combination of either midazolam and sufentanil or propofol and remifentanil. Pressure-controlled continuous mandatory ventilation (pc-CMV) was applied (SERVO-s/-I; Maquet, Rastatt,

\section{Table 1 Inclusion/exclusion criteria}

\begin{tabular}{ll}
\hline Inclusion criteria: & Exclusion criteria: \\
\hline $\begin{array}{l}\text { Ischaemic or haemorrhagic } \\
\text { stroke }\end{array}$ & $\circ$ Severe cardiac insufficiency \\
( $\mathrm{NYHA} \geq \mathrm{III})$
\end{tabular}


Germany) targeting for physiological levels of arterial blood gases $\left(\mathrm{PaO}_{2} 80\right.$ to $110 \mathrm{mmHg}, \mathrm{PaCO}_{2} 35$ to $\left.45 \mathrm{mmHg}\right)$.

\section{Interventions}

Patients were randomised to CI (intervention A) or NPC (intervention B).

Intervention A: Two litres of cold $\left(4^{\circ} \mathrm{C}\right)$ isotonic saline solution $(0.9 \% \mathrm{NaCl})$ were infused intravenously via a cubital vein catheter (18 gauge or larger) at a constant flow rate of 4. L/hour using a Power Infuser (ZOLL, Sunnyvale, CA, USA). We chose the same volume and infusion rate as employed in most cardiac arrest trials $[5,16]$ and implemented in previous and current stroke trials [9,11-15,24].

Intervention $B$ : NPC has been described in detail by others $[17,18]$. Briefly, NPC uses nasal catheters to spray an inert coolant (perfluorohexane) at a high flow rate into the nasal cavity. A lidocaine spray was applied before introduction of the nasal catheters. At treatment initiation, the flow rate was gradually increased over a period of 2 minutes until a rate of $60 \mathrm{~L} /$ minute was reached. NPC was applied for one hour.

During both interventions (A, B) no other cooling procedures were allowed.

\section{Outcome}

Because previous data suggested a maximum decrease of tympanic temperature for $\mathrm{CI}$ ( $2.1 \mathrm{~L}$ within 35 minutes) after 52 minutes, a study period of one-hour was chosen. The primary endpoint was defined as the change in brain temperature within one hour after treatment initiation. For better assessment of dynamic temperature changes, the one-hour study period was divided into four predefined subperiods of 15 minutes duration (I to IV). Secondary outcome measures were changes in body temperature at different extracerebral monitoring sites (tympanum, bladder, rectum and oesophagus), neurovital parameters (arterial pressure, cerebral perfusion pressure $[\mathrm{CPP}]$, heart rate $[\mathrm{HR}], \mathrm{ICP}$ and oxygen saturation $\left[\mathrm{SpO}_{2}\right]$ ) and ventilation parameters during the one-hour study period, and the assessment of various safety parameters, such as shivering, blood and blood gas analyses, bleeding complications, signs of acute heart failure, local irritations in the nasopharynx and olfactory dysfunction up to six months after cooling.

Critical values of neurovital parameters counted as severe $\mathrm{AE}$ and were predefined according to our local guidelines as follows: systolic arterial pressure (SAP) $>180$ $\mathrm{mmHg}$ in ischaemic stroke and $>160 \mathrm{mmHg}$ in haemorrhagic stroke; ICP >20 mmHg; CPP $<60 \mathrm{mmHg}$. Relevant delta values were defined as changes in SAP $>+20 \mathrm{mmHg}$ and ICP $>+10 \mathrm{mmHg}$. Shivering was graded using the bedside shivering assessment scale (BSAS, ranging from $0=$ no shivering to $3=$ severe shivering) [25]. BSAS scores of 3 were classified as severe AE. Blood samples for blood gas analyses and blood analysis were drawn before and two hours and twelve hours after the start of cooling [see Additional file 1]. Cranial CT before and after cooling induction and echocardiography were part of the routine diagnostic assessment and the images obtained were evaluated by neuroradiologists and cardiologists blinded for treatment allocation. Three days after cooling induction, patients underwent otorhinolaryngological (ORL) examination, including anterior and posterior rhinoscopy. ORL examination was repeated $\geq 6$ months after the intervention, adding a standardised 16-item smell test with Sniffin' Sticks. The ORL physicians were also blinded for treatment allocation.

Information about the medical equipment used can be found in the supplementary methods section [Additional file 2].

\section{Randomisation and blinding}

An independent physician randomly allocated groups, marked non-transparent envelopes sequentially, and sealed them. S.P. and C.H. obtained the patient consents and opened the envelopes in predefined order. Patients were randomised at a 1:1 ratio to either of the two interventions: (A) CI or (B) NPC. All neuroradiologists, cardiologists and ORL physicians who examined the patients were blinded to group allocation.

\section{Statistics}

Statistical analysis was performed using MATLAB v7.12 (MathWorks, Natick, MA, USA) and SAS v9.2 (SAS, Cary, NC, USA). The duration of baseline reading (15 minutes), the division of the one-hour interventional period into four subperiods (I to IV, 15 minutes each) and statistical analyses were predefined in the study protocol. Repeatedmeasurements analysis of variance (ANOVA) with the between-subject effect GROUP (CI versus NPC) and the within-subject effect TIME (five measurements: baseline, interventional periods I to IV) was used for the main statistical analysis (correction according to Greenhouse and Geisser). Further information is given in the supplementary statistics section [see Additional file 2].

\section{Results}

The study flow chart is shown in Figure 1. A total of 20 patients were enrolled in the study. Ten patients (seven ischaemic, three haemorrhagic stroke) received $2 \mathrm{~L}$ of $\mathrm{CI}$ in $33 \pm 4$ minutes and ten patients (four ischaemic, six haemorrhagic stroke) were treated with NPC for 60 minutes.

Baseline characteristics and outcome data are shown in Table 2. 


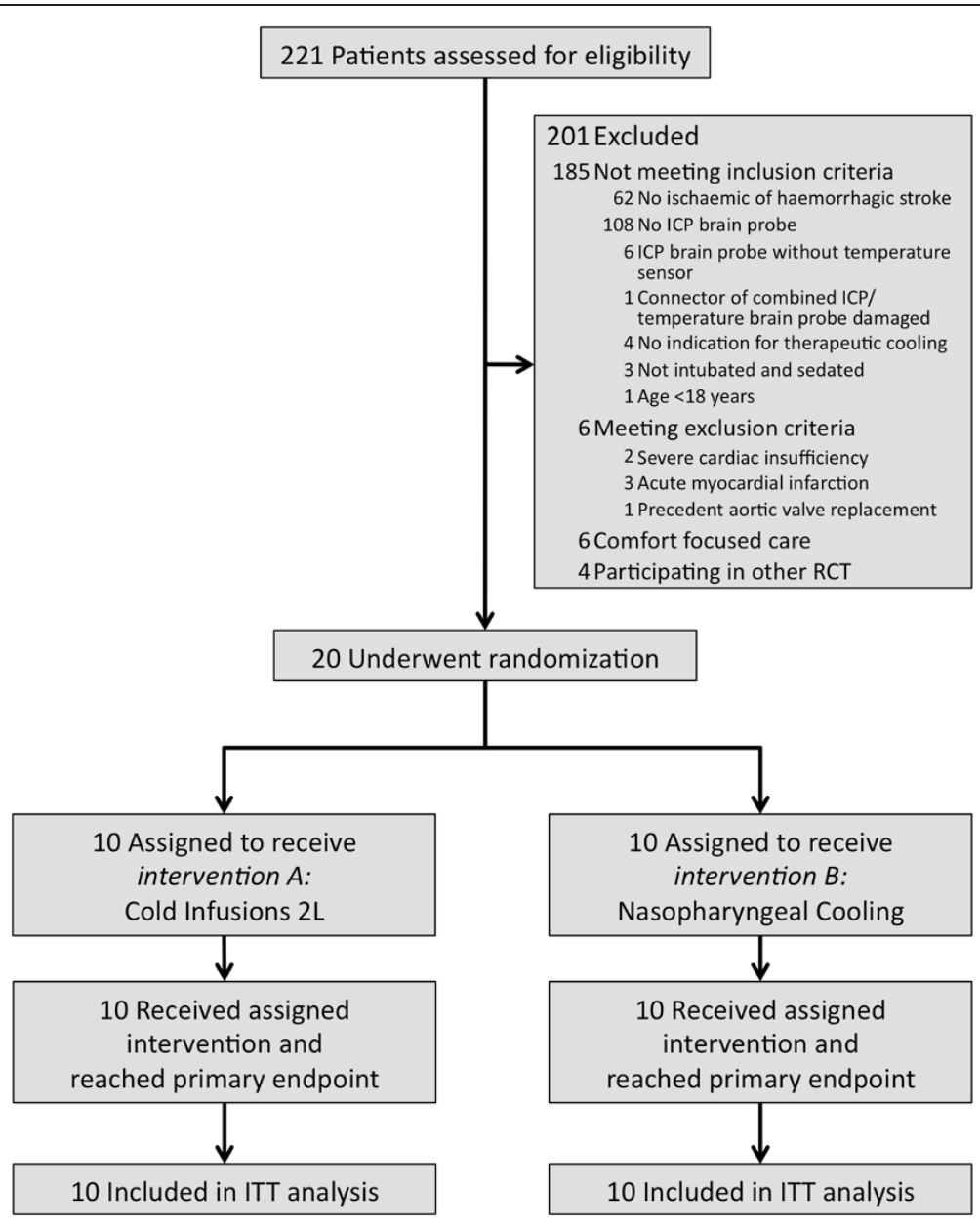

Figure 1 Study flow chart.

\section{Primary measurement: brain temperature}

Brain temperature was similar in the two study groups at baseline (CI $37.4 \pm 0.4^{\circ} \mathrm{C}$ versus NPC $37.5 \pm 1.1^{\circ} \mathrm{C}$, n.s.), but differed significantly during the intervention (see Figure 2A): during the first 30 minutes of active treatment with CI (subperiods I and II) brain temperature decreased faster than during NPC (I: $-0.31 \pm$ 0.2 versus $-0.12 \pm 0.1^{\circ} \mathrm{C}, P=0.008$; II: $-1.0 \pm 0.3$ versus $-0.49 \pm 0.3^{\circ} \mathrm{C}, P=0.001$, after 30 minutes: $-1.31 \pm 0.4$ versus $\left.-0.68 \pm 0.3^{\circ} \mathrm{C}, P<0.001\right)$. In the $\mathrm{CI}$ group, after the infusion was discontinued, the intervention did not have a further decreasing effect on brain temperature, but brain temperature increased again after $3.5 \pm 3.3$ minutes. In the NPC group, after an initial increase, the brain cooling rate slightly decreased again during the course of active treatment (I: $-0.12 \pm 0.1^{\circ} \mathrm{C}$, II: $-0.37 \pm 0.1^{\circ} \mathrm{C}$, III: $-0.34 \pm$ $0.1^{\circ} \mathrm{C}$, IV: $-0.27 \pm 0.1^{\circ} \mathrm{C}$; after 60 minutes: $-1.23 \pm 0.4^{\circ} \mathrm{C}$ ). All brain probes were inserted $>3 \mathrm{~cm}$ below the cortical surface. In the NPC group the distance between the probe tip and the nasopharynx was $6.6 \pm 1.7 \mathrm{~cm}$. Only age differed significantly between the two groups (see Table 2 ) and body surface area (BSA) correlated with brain cooling during NPC ( $r=0.6, P=0.049)$. Considering that, we additionally performed analysis of covariance (ANCOVA) with age and BSA as covariates; this analysis yielded comparable results. All other influencing variables (including stroke type) listed in the supplementary statistics section [see Additional file 2] tested negative for correlation with brain cooling.

\section{Secondary measurements \\ Surrogate temperature sites}

Data for surrogate temperature sites were available as follows: tympanum (20/20), bladder $(20 / 20)$, rectum (CI 6/10, NPC 5/10), and oesophagus (CI 6/10, NPC 6/10). At baseline, body temperature at all sites was similar to brain temperature, with the exception of tympanic temperature, which was slightly lower $(37.5 \pm 0.7$ versus $\left.37.1 \pm 0.7^{\circ} \mathrm{C}, P<0.001\right)$. During both interventions oesophageal temperature correlated best with brain temperature (n.s. for difference; see Figure 2B), whereas decreases in bladder $(P<0.001)$ and rectal temperature 
Table 2 Baseline characteristics and outcomes

\begin{tabular}{|c|c|c|c|}
\hline & $\begin{array}{c}\text { Cold } \\
\text { infusion }\end{array}$ & $\begin{array}{l}\text { Nasopharyngeal } \\
\text { cooling }\end{array}$ & $P$-value \\
\hline Patients; number & 10 & 10 & \\
\hline Female; number (\%) & $4(40 \%)$ & $5(50 \%)$ & n.s. ${ }^{a}$ \\
\hline Age, years; mean \pm STD & $65.4 \pm 7.4$ & $55.7 \pm 11.5$ & $0.038^{b}$ \\
\hline Weight, kg & $83.5 \pm 17.7$ & $80.3 \pm 12.7$ & n.s. ${ }^{b}$ \\
\hline Height, cm & $173.1 \pm 10.1$ & $172 \pm 10$ & n.s. ${ }^{b}$ \\
\hline Body mass index, $\mathrm{kg} / \mathrm{m}^{2}$ & $27.9 \pm 5.9$ & $27.3 \pm 2.4$ & n.s. ${ }^{b}$ \\
\hline Body surface area ${ }^{d}, \mathrm{~m}^{2}$ & $2 \pm 0.2$ & $2 \pm 0.2$ & n.s. ${ }^{b}$ \\
\hline $\begin{array}{l}\text { Time from symptom onset } \\
\text { to treatment, hours }\end{array}$ & $69.4 \pm 25.2$ & $67.1 \pm 31.9$ & n.s. ${ }^{b}$ \\
\hline Stroke type; number (\%) & & & n.s. ${ }^{a}$ \\
\hline Ischaemic & $7(70 \%)$ & $4(40 \%)$ & \\
\hline $\mathrm{ICH}$ & $2(20 \%)$ & $5(50 \%)$ & \\
\hline $\mathrm{SAH}$ & $1(10 \%)$ & $1(10 \%)$ & \\
\hline \multicolumn{4}{|l|}{ Scores } \\
\hline $\begin{array}{l}\text { Premorbid mRS; } \\
\text { number }(\%)\end{array}$ & & & n.s. ${ }^{c}$ \\
\hline 0 & $7(70 \%)$ & $7(70 \%)$ & \\
\hline 1 & $2(20 \%)$ & $2(20 \%)$ & \\
\hline 2 & $1(10 \%)$ & $1(10 \%)$ & \\
\hline $\begin{array}{l}\text { NIHSS admission; } \\
\text { median (IQR) }\end{array}$ & $\begin{array}{c}14.5(6.75- \\
24.75)\end{array}$ & $26.5(17.5-38)$ & n.s. ${ }^{c}$ \\
\hline $\begin{array}{l}\text { mRS follow-up } \\
\text { median (IQR) }\end{array}$ & $4.5(3.75-6)$ & $4.5(3-6)$ & n.s. $^{c}$ \\
\hline \multicolumn{4}{|l|}{ Risk factors; number (\%) } \\
\hline Diabetes mellitus & $0(0 \%)$ & $3(30 \%)$ & n.s. ${ }^{a}$ \\
\hline Arterial hypertension & $8(80 \%)$ & $8(80 \%)$ & n.s. ${ }^{a}$ \\
\hline Hypercholesterolaemia & $0(0 \%)$ & $1(10 \%)$ & n.s. ${ }^{a}$ \\
\hline Atrial fibrillation & $2(20 \%)$ & $0(0 \%)$ & n.s. ${ }^{a}$ \\
\hline
\end{tabular}

${ }^{\mathrm{a}}$ Fisher's exact test; ${ }^{\mathrm{b}}$ Student's $t$-test; ${ }^{\mathrm{C}}$ Mann-Whitney $U$ test.; ${ }^{\mathrm{d}}$ Mosteller formula. ICH, intracerebral haemorrhage; IQR, interquartile range; $m R S$, modified Rankin Scale; NIHSS, National Institutes of Health Stroke Scale; n.s. non-significant; SAH, subarachnoid haemorrhage; STD, standard deviation.

(CI $P=0.011$, NPC $P<0.001$ ) lagged distinctly in both groups. Tympanic temperature correlated well with brain temperature changes in patients receiving $\mathrm{CI}$ (n.s. for difference), but overestimated brain cooling in NPC-treated patients $(P=0.005)$.

\section{Neurovital parameters}

Mean continuous curves of SAP, CPP, ICP and HR for each intervention are given in Figure 3. In the CI group, $\mathrm{SAP}$, mean arterial pressure (MAP) and CPP were significantly higher than baseline in all subperiods (I to IV) and ICP was significantly increased during subperiods I to III ( $P<0.05$ for all). During NPC, only SAP and MAP were significantly higher than baseline, and only in subperiod I. In both groups, the level of sedation (RASS -5) remained unchanged during the one-hour study period, and the changes of neurovital parameters did not correlate with the underlying stroke type and the sedation regimen.

Direct comparison of CI and NPC showed significantly higher values in the CI group in subperiod II for SAP, MAP, CPP and ICP $(P<0.05)$. MAP and ICP were still significantly higher in subperiod III $(P<0.05)$. HR and $\mathrm{SpO}_{2}$ saturation exhibited no significant differences between CI and NPC throughout the observation period.

CI provoked eleven intervention-related AEs of neurovital parameters during subperiods II to IV, of which three were classified as severe (two SAP, one shivering). In contrast, all eight NPC-associated AEs were confined to subperiod I. Four were classified as severe (three SAP, one ICP). Severe AEs were treated according to the local standard guidelines for management of BP, ICP and shivering. Intervention-related complications of individual patients are listed in Table 3.

\section{Respiratory parameters}

Inspiratory tidal volume decreased during both interventions, although ventilator settings were kept stable. Changes were significant compared with baseline during subperiods II to IV in the CI group and during subperiods III and IV in the NPC group $(P<0.05$; see Figure $3 C)$. In subperiods II and III, inspiratory tidal volume decreased to a greater extent in the $\mathrm{CI}$ than in the NPC group $(P<0.05)$.

\section{Ventilator malfunction}

Two cases of ventilator failure (SERVO-I) occurred during NPC - 56 minutes and 24 minutes after treatment start. In both cases, a change of the expiration cassette resolved the issue. Ventilation was bypassed with an Oxylog3000 (Draeger, Luebeck, Germany) for sixteen minutes and six minutes, respectively. The lowest $\mathrm{SpO}_{2}$ was $95 \%$ and $98 \%$. We classified both events as possible intervention-related unanticipated serious adverse device effects (USADE).

\section{Chart and laboratory assessment}

CI significantly affected volume balance compared with baseline and with the NPC group (CI 1,989 $\pm 190 \mathrm{ml}$ versus NPC $0 \pm 188 \mathrm{ml}, P<0.001)$. No differences in laboratory values (including arterial blood gases) between the two treatment groups were found at any time. The supplementary table presents the detailed laboratory values [see Additional file 1].

\section{Imaging}

Safety evaluation of brain imaging revealed no new bleeding events. In one patient the CT scan after NPC showed a retention of fluid perfluorohexane (PFH; 560 Hounsfield units) in the left sphenoid sinus [20]. This 


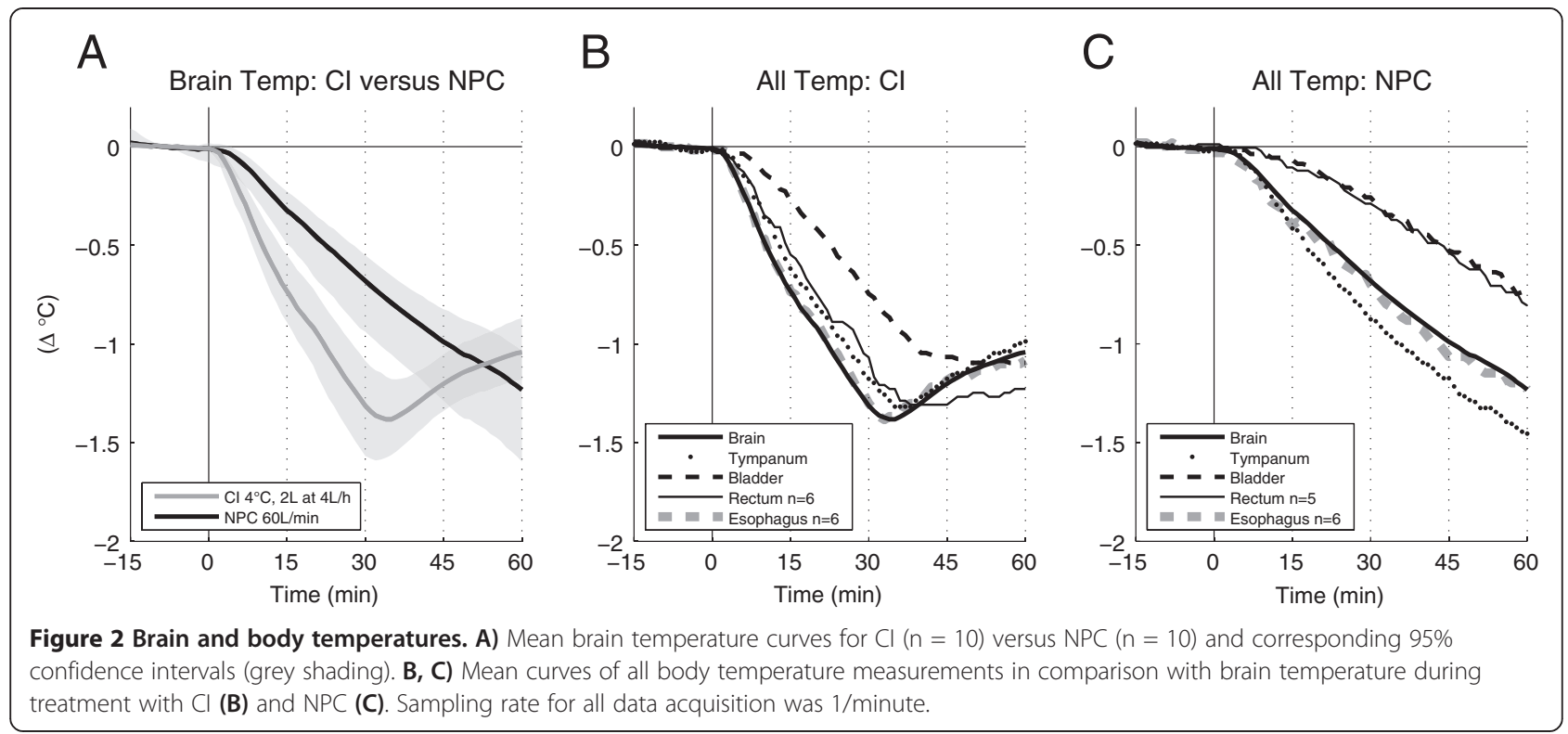

PFH retention had spontaneously resolved by the next CT examination two days later.

\section{Otorhinolaryngological evaluation}

ORL evaluation on day 3 was available for 17 patients (CI 8/10, NPC 9/10). Overall, we observed four mild AEs without the necessity of further treatment, two in each interventional group. One patient in the CI group experienced minor bleeding at the larynx, which most likely occurred after tracheotomy was performed. In another patient of the CI group, ichor but no mucosal defect was found. One patient in the NPC group developed an epipharyngeal haematoma, and another suffered from swollen nasal conchae. These two AEs were classified as possibly intervention-related.

ORL evaluation at follow-up ( $>6$ months) was available in 10 patients (of the remainder, six had died, while four declined examination). Rhinoscopic findings (CI five, NPC five) and the 16-item smell test with Sniffin' Sticks (CI three, NPC five) were normal in all tested patients.

\section{Discussion}

Induction methods for therapeutic cooling are underinvestigated [4]. For the first time, the iCOOL1 trial provides data on the effects of $\mathrm{CI}$ on brain temperature and neurovital parameters, demonstrates that oesophageal
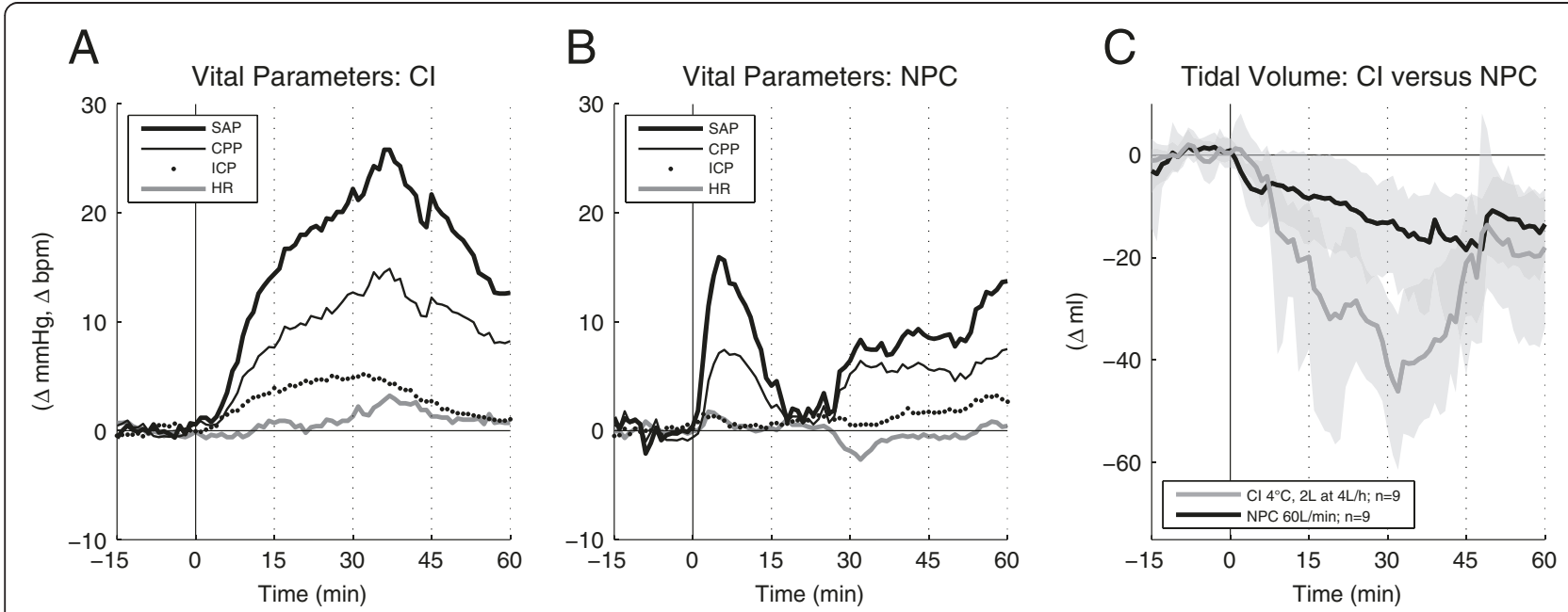

Figure 3 Neurovital and respiratory parameters. A, B) Mean curves of neurovital parameters during $C l(A ; n=10)$, and NPC (B; $n=10)$. SAP, systolic arterial pressure; CPP, cerebral perfusion pressure; ICP, intracranial pressure; HR, heart rate. $\mathrm{C}$ ) Mean inspiratory tidal volume curves for $\mathrm{Cl}$ $(n=9)$ versus NPC $(n=9)$ and corresponding 95\% confidence intervals (grey shading); respiratory data were not available for one patient in each interventional group. Sampling rate for all data acquisition was $1 /$ minute. 
Table 3 Intervention-related AE

\begin{tabular}{|c|c|c|c|c|c|}
\hline ID & Intervention & Stroke type & Intervention-related AE & Subperiod & Treatment \\
\hline 2 & $\mathrm{Cl}$ & Ischaemic & No & - & - \\
\hline 3 & $\mathrm{Cl}$ & Ischaemic & BSAS 3 & $\|$ & Yes \\
\hline 4 & $\mathrm{Cl}$ & Ischaemic & $\triangle S A P+42 \mathrm{mmHg}$, SAP $186 \mathrm{mmHg}$ & III & $\mathrm{No}^{\mathrm{a}}$ \\
\hline 6 & $\mathrm{Cl}$ & $\mathrm{ICH}$ & $\triangle \mathrm{SAP}+33 \mathrm{mmHg}$ & III & No \\
\hline 9 & $\mathrm{Cl}$ & $\mathrm{ICH}$ & $\triangle \mathrm{SAP}+43 \mathrm{mmHg}$ & III & No \\
\hline 13 & $\mathrm{Cl}$ & Ischaemic & $\triangle \mathrm{SAP}+39 \mathrm{mmHg}, \mathrm{ICP} 27 \mathrm{mmHg}$ & $\|$ & Yes \\
\hline 15 & $\mathrm{Cl}$ & Ischaemic & No & - & - \\
\hline 16 & $\mathrm{Cl}$ & Ischaemic & $\triangle \mathrm{SAP}+43 \mathrm{mmHg}$ & III & No \\
\hline 17 & $\mathrm{Cl}$ & Ischaemic & $\triangle \mathrm{SAP}+28 \mathrm{mmHg}$ & III & No \\
\hline 19 & $\mathrm{Cl}$ & $\mathrm{SAH}$ & $\triangle \mathrm{SAP}+18 \mathrm{mmHg}$, SAP $165 \mathrm{mmHg}$ & IV & Yes \\
\hline 1 & NPC & Ischaemic & $\triangle \mathrm{SAP}+35 \mathrm{mmHg}$ & । & No \\
\hline 5 & NPC & $\mathrm{ICH}$ & No & - & - \\
\hline 7 & NPC & $\mathrm{ICH}$ & BSAS 3 & । & Yes \\
\hline 8 & NPC & $\mathrm{SAH}$ & $\triangle \mathrm{SAP}+14 \mathrm{mmHg}$, SAP $160 \mathrm{mmHg}$ & । & Yes \\
\hline 10 & NPC & Ischaemic & $\triangle \mathrm{SAP}+28 \mathrm{mmHg}$, SAP $187 \mathrm{mmHg}$ & । & Yes \\
\hline 11 & NPC & $\mathrm{ICH}$ & $\triangle \mathrm{SAP}+40 \mathrm{mmHg}$ & । & No \\
\hline 12 & NPC & Ischaemic & $\triangle \mathrm{SAP}+51 \mathrm{mmHg}, \mathrm{ICP} 27 \mathrm{mmHg}$ & । & Yes \\
\hline 14 & NPC & $\mathrm{ICH}$ & No & - & - \\
\hline 18 & NPC & $\mathrm{ICH}$ & No & - & - \\
\hline 20 & NPC & Ischaemic & $\triangle \mathrm{SAP}+25 \mathrm{mmHg}$ & । & No \\
\hline
\end{tabular}

${ }^{a} \mathrm{SAP}$ rose to $186 \mathrm{mmHg}$, but resolved spontaneously before treatment was initiated. Intervention-related AE of neurovital parameters for each patient, with the time of occurrence (subperiods I to IV), and whether or not the AE was treated. Treatment was indicated if SAP or ICP was higher than the predefined critical value (SAP ischaemic stroke $\geq 180 \mathrm{mmHg}$, haemorrhagic stroke $\geq 160 \mathrm{mmHg} ; \mathrm{ICP} \geq 20 \mathrm{mmHg}$ ), or the BSAS score was $\geq 1$. $\triangle$ SAP indicates maximum delta SAP compared to baseline. BSAS, Bedside Shivering Assessment Scale; ICH, intracerebral haemorrhage; ICP, intracranial pressure; SAH, subarachnoid haemorrhage; SAP, systolic arterial pressure.

temperature is the best extracerebral surrogate for brain temperature during $\mathrm{CI}$ and NPC, and compares the effectiveness and safety of CI and NPC for induction of cooling in stroke patients.

\section{Brain cooling is faster during $\mathrm{Cl}$ than during NPC}

Subperiods I and II, the two subperiods during which both groups were actively treated, revealed faster brain cooling during $\mathrm{CI}\left(-1.31^{\circ} \mathrm{C}\right.$ after 30 minutes) than during $\mathrm{NPC}\left(-0.68^{\circ} \mathrm{C}\right.$ after 30 minutes). In the $\mathrm{CI}$ group, brain temperature reduction stopped only 3.5 minutes after cessation of $\mathrm{CI}$, and brain temperature increased again (see Figure 2A). This is of great importance as it implies that additional methods for maintenance cooling should be commenced by the end of CI infusion in order to avoid fluctuations of brain temperature. Repetition of $\mathrm{CI}$ or infusion of higher volumes for bridging until maintenance cooling are most likely not an adequate solution owing to the high risk of harmful fluid overload [16]. On the other hand, it seems possible to stretch the duration of CI by decreasing the infusion rate. However, this would probably result in a loss of cooling efficiency. This is even more important, as the fast brain cooling with CI in our trial was obtained with a well-controlled
CI temperature of $4^{\circ} \mathrm{C}$, which cannot be guaranteed under all circumstances [26,27].

NPC yielded a continuous decrease throughout the 60 minutes of active treatment and reached $-1.23^{\circ} \mathrm{C}$ at the end of subperiod IV. This finding is consistent with brain-cooling rates in patients who suffered traumatic brain injury or stroke, as previously described by AbouChebl et al. and our group [19,20]. In our observational period of one hour we captured the post-treatment period for the CI group, because an immediate increase of brain temperature after CI cessation occurred. However, since this was rather unexpected, this was not studied in the NPC group. As suggested by Abou-Chebl and colleagues we recorded the site of the brain temperature measurement (probe tip), as this may influence cooling rates during NPC [19]. The one-hour cooling rate $(-1.2$ versus $-1.23^{\circ} \mathrm{C}$ ) and the distance from the probe to the nasopharynx $(6.6$ versus $6.4 \mathrm{~cm})$ were comparable in the two studies [20].

$\mathrm{Yu}$ and colleagues directly compared CI and NPC in a porcine model of prolonged cardiac arrest and reported that jugular vein temperature (measured as a surrogate for brain temperature) decreased faster in pigs treated with NPC [28]. This contrasts with our observation of 
faster brain cooling during CI. The closer anatomical proximity of the nasopharynx to a smaller brain and the existence of the rete mirabile in pigs relative to humans as well as the preserved cardiac circulation in stroke patients may explain these different findings. Considerations drawn from porcine cardiac arrest experiments measuring brain temperature, that NPC primarily cools the brain $[29,30]$ are not supported by our results in stroke patients; in our study, oesophageal body core temperature decreased to the same degree as brain temperature.

\section{Bladder temperature is unsuitable as a surrogate for brain temperature during induction of cooling with $\mathrm{Cl}$ or NPC}

Very limited reports have been published on surrogate monitoring sites for brain temperature during rapid temperature changes [31,32]. Until now, data comparing brain temperature with temperatures in other parts of the body during CI have been completely lacking.

In this study, temperature changes in bladder and rectum, the most commonly used standard monitoring sites for body core temperature in the ICU, failed to promptly replicate brain temperature changes in both study groups (Figure 2B,C). This is in accordance with the results of Stone and colleagues, who investigated body temperatures in patients undergoing deep hypothermic circulatory arrest [32]. These authors also classified bladder and rectal temperature measurements as unsuitable for detecting rapid changes in brain temperature. Decreases in oesophageal temperature, on the other hand, were found to be accurate [32]. For the first time we can now confirm these findings for CI and NPC.

Our findings are of great importance: All but one [33] of the previously published large cardiac arrest/cooling induction trials that used CI $[5,16,26]$ or NPC $[17,18]$ monitored the slow-reacting bladder or rectal temperatures, or did not distinguish between core temperatures in different parts of the body but rather reported a composite core temperature. Furthermore, none of these studies monitored body temperature at the same site during cooling induction and maintenance cooling. It is, therefore, very unlikely that the fast increase of brain temperature after $\mathrm{CI}$ cessation would have been detected in those trials [34].

\section{Intervention-related AE of neurovital parameters in} NPC-treated patients appear instantly, whereas onset is delayed in patients receiving $\mathrm{Cl}$

Our findings confirm our previous observation [20] that NPC may provoke immediate BP peaks even in deeply sedated patients and independent of stroke type (see Table 3). In our study, additional bolus medication reliably resolved these $\mathrm{BP}$ peaks. The BP increase we observed during CI seems to be directly linked to the administered volume of fluid and also did not correlate with the underlying stroke type. Tollofsrud et al. and Polderman et al. also found transient BP increases after $\mathrm{CI}$ in healthy volunteers and brain-injured patients $[13,35]$. In contrast, Kollmar and colleagues reported no $\mathrm{BP}$ increases in ten awake ischaemic stroke patients; however, they took measurements at 30-minute intervals, which limits comparability [11].

Importantly, even though both induction methods induced significant BP increases, brain imaging analysis showed no intracranial bleeding complications, also in those patients with haemorrhagic stroke. Nevertheless, our observation of blood pressure increases in both groups raises serious safety concerns especially when treating hyperacute haemorrhagic stroke.

In contrast to NPC, CI induced a more or less pronounced ICP increase in all patients, which, for the most part, can also be ascribed to the intravascular volume increase with a consecutive shift of intracranial compartments.

Furthermore, inspiratory tidal volume decreased to a noteworthy extent. Since patients remained deeply sedated (RASS -5) and ventilator settings of pc-CMV were not changed during the one-hour study period, an increase in respiratory resistance due to volume expansion [36] and cooling [37] may explain this finding.

We registered two cases of ventilator failure during NPC. Both malfunctions were unanticipated and serious (USADE) and are possibly intervention-related. In both cases, a change of the expiration cassette resolved the issue.

In summary, our findings of increased BP and ICP as well as other intervention-related and possibly interventionrelated AEs raise concern regarding the safety of $\mathrm{CI}\left(4^{\circ} \mathrm{C}\right.$, $2 \mathrm{~L}$ at $4 \mathrm{~L}$ /hour) and NPC in stroke patients. Further study of safety is imperative before broader use.

\section{Limitations}

Our study has some limitations. Group sizes in this randomised trial were rather small. However, a clearly defined endpoint using repeated-measurements ANOVA with a size of 10 in each group provided significant and robust results. The lack of a control group without cooling was inevitable, as inclusion was coupled to the study-independent indication for therapeutic cooling. We enrolled patients with different stroke entities (ischaemic stroke, ICH and $\mathrm{SAH}$ ), but neither during $\mathrm{CI}$ nor during NPC brain cooling correlated with the underlying stroke type. Furthermore, both the frequency and the severity of adverse events were similar for the different stroke types and interventions (see Table 3). The requirement for brain temperature measurement inevitably leads to selection bias, as nearly all patients with an ICP/temperature brain probe are severely affected and all were intubated and sedated. Therefore, the findings of this study cannot be generalised to the very large majority of patients who are only 
mildly affected by stroke or who are treated in a prehospital setting. Fewer than $10 \%$ of patients with ischaemic stroke need intubation, a prerequisite for NPC [38]. As this trial was performed in one centre only, external validation of the results is necessary.

\section{Conclusions}

In intubated stroke patients brain cooling is faster during active treatment with $\mathrm{CI}\left(4^{\circ} \mathrm{C}, 2 \mathrm{~L}\right.$ at $4 \mathrm{~L} /$ hour $)$ than during NPC. Importantly, contrary to previous expectations, brain cooling stopped soon after $\mathrm{CI}$ cessation. Our finding implies that additional methods for maintenance cooling should be commenced by the end of $\mathrm{CI}$ infusion in order to avoid fluctuations of brain temperature. NPC may be an alternative in intubated stroke patients when infusion of high volumes is contraindicated. Oesophageal, but neither bladder nor rectal temperature, is suited as surrogate for brain temperature during CI and NPC. Tympanic temperature seems feasible, too, during CI, when a certain offset in absolute values is kept in mind. Several severe adverse events in $\mathrm{CI}$ and in NPC demand further studying of safety.

\section{Key messages}

- First study showing the effect of $\mathrm{CI}$ on brain temperature

- Brain cooling is faster during $\mathrm{CI}\left(4^{\circ} \mathrm{C}, 2 \mathrm{~L}\right.$ at $4 \mathrm{~L} /$ hour $)$ than during NPC.

- Brain temperature increases again soon after discontinuation of $\mathrm{CI}$.

- Intervention-related $\mathrm{AEs}$ raise concern regarding the safety of $\mathrm{CI}\left(4^{\circ} \mathrm{C}, 2 \mathrm{~L}\right.$ at $4 \mathrm{~L} /$ hour $)$ and NPC in stroke patients.

- Oesophageal temperature is best suited as surrogate for brain temperature during both CI and NPC.

\section{Additional files}

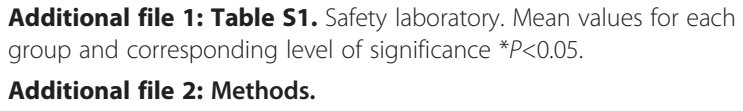

\section{Abbreviations}

AE: adverse effect; ANOVA: analysis of variance; BP: blood pressure; BSA: body surface area; BSAS: Bedside Shivering Assessment Scale; Cl: cold infusion; CPP: cerebral perfusion pressure; CT: computed tomography; HR: heart rate; ICP: intracranial pressure; iCOOL1: Rapid Induction of COOLing in Stroke Patients trial; MAP: mean arterial pressure; NPC: nasopharyngeal cooling; ORL: otorhinolaryngological; pc-CMV: pressure-controlled continuous perfusion pressure; PFH: perfluorohexane; RASS: Richmond Agitation Sedation Scale; SAP: systolic arterial pressure; $\mathrm{SpO}_{2}$ : oxygen saturation.

\section{Competing interests}

RhinoChill system and supplies were provided by BeneChill, Inc., San Diego, CA, USA. The Power Infuser and supplies were provided by ZOLL, Sunnyvale, CA, USA. Neuromonitoring equipment was provided by Covidien and Raumedic. Neither company had any influence whatsoever on patient enrolment, data acquisition, data interpretation or drafting of the manuscript.
SP has received speaker's fees from C.R. Bard, BeneChill, EMCOOLS, and ZOLL, and research grants from EMCOOLS and ZOLL. All other authors declare that they have no competing interests.

\section{Authors' contributions}

All authors made substantial contributions to the study: SP, CH and JP conceived and designed the research, acquired the data, analysed and interpreted the data, performed statistical analysis, handled funding, drafted the manuscript and critically revised the manuscript for important intellectual content. MP, CB and MS acquired the data, and critically revised the manuscript for important intellectual content. JD and AR analysed and interpreted the data, performed statistical analysis, and critically revised the manuscript for important intellectual content. ME and EP critically revised the manuscript for important intellectual content. All authors read and approved the final manuscript.

\section{Acknowledgements}

We thank Werner Hacke, MD PhD, departmental chairman, for providing the clinical and research environment and for his scientific and professional support. We thank Julian Bösel, MD, consultant neurologist responsible for the NICU, for his professional support. We thank Thorsten Steiner, MD, medical director of the Department of Neurology, Frankfurt Hoechst Hospital, for his excellent teaching and scientific support. We thank Zhongying Peng, $\mathrm{MD}$, for preparation of randomisation envelopes.

\section{Author details}

1Department of Neurology, Heidelberg University, INF 400, 69120 Heidelberg, Germany. ${ }^{2}$ Department of Neurology \& Stroke, Tuebingen University, Hoppe-Seyler-Str. 3, 72076 Tuebingen, Germany. ${ }^{3}$ Department of ENT, Heidelberg University, INF 400, 69120 Heidelberg, Germany. ${ }^{4}$ Department of Anaesthesiology, Heidelberg University, INF 110, 69120 Heidelberg, Germany.

Received: 31 March 2014 Accepted: 8 October 2014

Published online: 27 October 2014

\section{References}

1. Zhao H, Steinberg G: Limited therapeutic time windows of mild-tomoderate hypothermia in a focal ischemia model in rat. Stroke Res Treat 2011, 2011:131834

2. Kuboyama K, Safar P, Radovsky A, Tisherman SA, Stezoski SW, Alexander H: Delay in cooling negates the beneficial effect of mild resuscitative cerebral hypothermia after cardiac arrest in dogs: a prospective, randomized study. Crit Care Med 1993, 21:1348-1358.

3. Holzer M: Devices for rapid induction of hypothermia. Eur J Anaesthesiol Suppl 2008, 42:31-38.

4. Taccone FS, Donadello K, Beumier M, Scolletta S: When, where and how to initiate hypothermia after adult cardiac arrest. Minerva Anestesio/ 2011, 77:927-933.

5. Arulkumaran N, Suleman R, Ball J: Use of ice-cold crystalloid for inducing mild therapeutic hypothermia following out-of-hospital cardiac arrest. Resuscitation 2012, 83:151-158.

6. Peberdy MA, Callaway CW, Neumar RW, Geocadin RG, Zimmerman JL, Donnino M, Gabrielli A, Silvers SM, Zaritsky AL, Merchant R, Vanden Hoek TL, Kronick SL, American Heart Association: Part 9: post-cardiac arrest care: 2010 American Heart Association Guidelines for Cardiopulmonary Resuscitation and Emergency Cardiovascular Care. Circulation 2010, 122:S768-S786.

7. Nolan JP, Soar J, Zideman DA, Biarent D, Bossaert LL, Deakin C, Koster RW Wyllie J, Bottiger B, ERC Guidelines Writing Group: European resuscitation council guidelines for resuscitation 2010 section 1. Executive summary. Resuscitation 2010, 81:1219-1276

8. Lyden PD, Hemmen TM, Grotta J, Rapp K, Raman R: Endovascular therapeutic hypothermia for acute ischemic stroke: ICTuS 2/3 protocol. Int J Stroke 2014, 9:117-125.

9. van der Worp HB, Macleod MR, Bath PM, Demotes J, Durand-Zaleski I, Gebhardt B, Gluud C, Kollmar R, Krieger DW, Lees KR, Molina C, Montaner J, Roine RO, Petersson J, Staykov D, Szabo I, Wardlaw JM, Schwab S, EuroHYP-1 investigators: EuroHYP-1: European multicenter, randomized, phase III clinical trial of therapeutic hypothermia plus best medical treatment vs. best medical treatment alone for acute ischemic stroke. Int J Stroke 2014, 9:642-645. 
10. Busto R, Dietrich WD, Globus MY, Valdes I, Scheinberg P, Ginsberg MD: Small differences in intraischemic brain temperature critically determine the extent of ischemic neuronal injury. J Cereb Blood Flow Metab 1987, 7:729-738.

11. Kollmar R, Schellinger PD, Steigleder T, Kohrmann M, Schwab S: Ice-cold saline for the induction of mild hypothermia in patients with acute ischemic stroke: a pilot study. Stroke 2009, 40:1907-1909.

12. Martin-Schild S, Hallevi H, Shaltoni H, Barreto AD, Gonzales NR, Aronowski J, Savitz SI, Grotta JC: Combined neuroprotective modalities coupled with thrombolysis in acute ischemic stroke: a pilot study of caffeinol and mild hypothermia. Int J Stroke 2009, 18:86-96.

13. Polderman KH, Rijnsburger ER, Peerdeman SM, Girbes AR: Induction of hypothermia in patients with various types of neurologic injury with use of large volumes of ice-cold intravenous fluid. Crit Care Med 2005, 33:2744-2751.

14. Hoedemaekers CW, Ezzahti M, Gerritsen A, van der Hoeven JG: Comparison of cooling methods to induce and maintain normo- and hypothermia in intensive care unit patients: a prospective intervention study. Crit Care 2007, 11:R91.

15. Ovesen C, Brizzi M, Pott FC, Thorsen-Meyer HC, Karlsson T, Ersson A, Christensen H, Norrlin A, Meden P, Krieger DW, Petersson J: Feasibility of endovascular and surface cooling strategies in acute stroke. Acta Neurol Scand 2013, 127:399-405.

16. Kim F, Nichol G, Maynard C, Hallstrom A, Kudenchuk PJ, Rea T, Copass MK, Carlbom D, Deem S, Longstreth WT Jr, Olsufka M, Cobb LA: Effect of prehospital induction of mild hypothermia on survival and neurological status among adults with cardiac arrest: a randomized clinical trial. JAMA 2014, 311:45-52.

17. Busch HJ, Eichwede F, Fodisch M, Taccone FS, Wobker G, Schwab T, Hopf HB, Tonner P, Hachimi-Idrissi S, Martens P, Fritz H, Bode C, Vincent JL, Inderbitzen B, Barbut D, Sterz F, Janata A: Safety and feasibility of nasopharyngeal evaporative cooling in the emergency department setting in survivors of cardiac arrest. Resuscitation 2010, 81:943-949.

18. Castren M, Nordberg P, Svensson L, Taccone F, Vincent JL, Desruelles D, Eichwede F, Mols P, Schwab T, Vergnion M, Storm C, Pesenti A, Pachl J, Guerisse F, Elste T, Roessler M, Fritz H, Durnez P, Busch HJ, Inderbitzen B, Barbut D: Intra-arrest transnasal evaporative cooling: a randomized, prehospital, multicenter study (PRINCE: Pre-ROSC IntraNasal Cooling Effectiveness). Circulation 2010, 122:729-736

19. Abou-Chebl A, Sung G, Barbut D, Torbey M: Local brain temperature reduction through intranasal cooling with the RhinoChill device: preliminary safety data in brain-injured patients. Stroke 2011, 42:2164-2169.

20. Poli S, Purrucker J, Priglinger M, Sykora M, Diedler J, Rupp A, Bulut C, Hacke W, Hametner C: Safety evaluation of nasopharyngeal cooling (RhinoChill $\left.{ }^{\oplus}\right)$ in stroke patients: an observational study. Neurocrit Care 2014, 20:98-105.

21. ClinicalTrials.gov. http://www.clinicaltrials.gov.

22. Saini M, Saqqur M, Kamruzzaman A, Lees KR, Shuaib A, VISTA Investigators: Effect of hyperthermia on prognosis after acute ischemic stroke. Stroke 2009, 40:3051-3059.

23. Schwab S, Schwarz S, Spranger M, Keller E, Bertram M, Hacke W: Moderate hypothermia in the treatment of patients with severe middle cerebral artery infarction. Stroke 1998, 29:2461-2466.

24. Hemmen T, Rapp K, Raman R, Concha M, Brössner G, Schmutzhard E, Tafreshi G, Misra V, Cruz-Flores S, Kollmar R, Brown D, Altafullah I, Michel P, Alexandrov A, Smith C, Jurf J, Hess MJ, Grotta J, Lyden PD: Phase 2/3 study of intravenous thrombolysis and hypothermia for acute treatment of ischemic stroke (ICTuS 2/3). Crit Care 2012, 16:A13.

25. Badjatia N, Strongilis E, Gordon E, Prescutti M, Fernandez L, Fernandez A Buitrago M, Schmidt JM, Ostapkovich ND, Mayer SA: Metabolic impact of shivering during therapeutic temperature modulation: the Bedside Shivering Assessment Scale. Stroke 2008, 39:3242-3247.

26. Bernard SA, Smith K, Cameron P, Masci K, Taylor DM, Cooper DJ, Kelly AM, Silvester W, Rapid Infusion of Cold Hartmanns Investigators: Induction of prehospital therapeutic hypothermia after resuscitation from nonventricular fibrillation cardiac arrest*. Crit Care Med 2012, 40:747-753.

27. Bernard SA, Smith K, Cameron P, Masci K, Taylor DM, Cooper DJ, Kelly AM, Silvester W, Rapid Infusion of Cold Hartmanns I: Induction of therapeutic hypothermia by paramedics after resuscitation from out-of-hospital ventricular fibrillation cardiac arrest: a randomized controlled trial. Circulation 2010, 122:737-742.
28. Yu T, Barbut D, Ristagno G, Cho JH, Sun S, Li Y, Weil MH, Tang W: Survival and neurological outcomes after nasopharyngeal cooling or peripheral vein cold saline infusion initiated during cardiopulmonary resuscitation in a porcine model of prolonged cardiac arrest. Crit Care Med 2010, 38:916-921.

29. Boller M, Lampe JW, Katz JM, Barbut D, Becker LB: Feasibility of intra-arrest hypothermia induction: a novel nasopharyngeal approach achieves preferential brain cooling. Resuscitation 2010, 81:1025-1030.

30. Wang H, Barbut D, Tsai MS, Sun S, Weil MH, Tang W: Intra-arrest selective brain cooling improves success of resuscitation in a porcine model of prolonged cardiac arrest. Resuscitation 2010, 81:617-621.

31. Mellergard $P$ : Changes in human intracerebral temperature in response to different methods of brain cooling. Neurosurgery 1992, 31:671-677. discussion 677.

32. Stone JG, Young WL, Smith CR, Solomon RA, Wald A, Ostapkovich N, Shrebnick DB: Do standard monitoring sites reflect true brain temperature when profound hypothermia is rapidly induced and reversed? Anesthesiology 1995, 82:344-351.

33. Kim F, Olsufka M, Longstreth WT Jr, Maynard C, Carlbom D, Deem S, Kudenchuk P, Copass MK, Cobb LA: Pilot randomized clinical trial of prehospital induction of mild hypothermia in out-of-hospital cardiac arrest patients with a rapid infusion of 4 degrees $C$ normal saline. Circulation 2007, 115:3064-3070.

34. Kliegel A, Janata A, Wandaller C, Uray T, Spiel A, Losert H, Kliegel M, Holzer M, Haugk M, Sterz F, Laggner AN: Cold infusions alone are effective for induction of therapeutic hypothermia but do not keep patients cool after cardiac arrest. Resuscitation 2007, 73:46-53.

35. Tollofsrud S, Bjerkelund CE, Kongsgaard U, Hall C, Noddeland H: Cold and warm infusion of Ringer's acetate in healthy volunteers: the effects on haemodynamic parameters, transcapillary fluid balance, diuresis and atrial peptides. Acta Anaesthesiol Scand 1993, 37:768-773.

36. Rubini A, Gasperetti A, Catena V, Del Monte D: Effects of acute blood volume expansion on respiratory mechanics in the rat. Respiration 2010, 79:497-505

37. Souhrada M, Souhrada JF: The direct effect of temperature on airway smooth muscle. Respir Physiol 1981, 44:311-323.

38. Gujjar AR, Deibert E, Manno EM, Duff S, Diringer MN: Mechanical ventilation for ischemic stroke and intracerebral hemorrhage: indications, timing, and outcome. Neurology 1998, 51:447-451.

doi:10.1186/s13054-014-0582-1

Cite this article as: Poli et al:: Rapid Induction of COOLing in Stroke Patients (iCOOL1): a randomised pilot study comparing cold infusions with nasopharyngeal cooling. Critical Care 2014 18:582.

\section{Submit your next manuscript to BioMed Central and take full advantage of:}

- Convenient online submission

- Thorough peer review

- No space constraints or color figure charges

- Immediate publication on acceptance

- Inclusion in PubMed, CAS, Scopus and Google Scholar

- Research which is freely available for redistribution 